\title{
Aquisição de escrita por alunos surdos: a categoria aspectual como um exemplo do processo
}

\author{
Writing Acquisition by Deaf Students: The \\ Aspectual Category as a Process Example
}

Rossana Finau*
Universidade Tecnológica Federal do Paraná
Curitiba - Paraná / Brasil

\begin{abstract}
RESUMO: O objetivo deste trabalho é investigar a formação de interlíngua no processo de aquisição de escrita da Língua Portuguesa por alunos surdos. Para esse propósito, a categoria aspectual é o principal objeto de análise, a partir das propostas teóricas dos trabalhos de Jake (1998), White (2003), Ilari (1997), Castilho (1994), entre outros. Os resultados da investigação indicam a formação da interlíngua no processo de aquisição de segunda língua, bem como a influência do período em que os alunos entraram em contato com a Libras para organização gramatical da língua alvo. Esses resultados permitem apontar a hipótese de que é importante que os alunos surdos tenham acesso à escrita da língua de sinais como apoio para a aprendizagem da modalidade escrita da oral. PALAVRAS-CHAVE: Aquisição de segunda língua, Formação de interlíngua, Libras, Português escrito, Aspecto.
\end{abstract}

\begin{abstract}
This study aims to investigate the formation of interlanguage in the acquisition of written Portuguese by deaf students. For this purpose, the aspectual category is the main object of analysis, as set forth in the theoretical proposals from Jake (1998), White (2003), Ilari (1997), Castillo (1995), among others. The research results indicate the formation of interlanguage in the second language acquisition process, as well as the influence of the period in which students came in contact with Brazilian Sign Language (Libras) for the grammatical organization of the target language. These results support the hypothesis that it is important for deaf students to have access to written sign language as a tool for learning the written form of the spoken language.

KEYWORDS: Second language acquisition, Interlanguage, Libras, Written Portuguese, Aspect.
\end{abstract}

*rfinau@hotmail.com 


\section{Introdução}

Com o advento dos estudos linguísticos realizados com línguas de sinais, o aluno surdo tem conseguido ferramentas importantes para garantir o seu direito a uma abordagem bilíngue na condução de seu processo educacional. Isso se deve muito ao fato de, cada vez mais, as investigaçóes linguísticas apresentarem argumentos definitivos que comprovam ser um equívoco pensar na existência de primazia da modalidade oral de linguagem sobre a de sinais. Esse é um dogma que não se sustenta cientificamente. Entretanto, embora exista o recente reconhecimento da língua, ainda são poucas as pesquisas e trabalhos que abordam a educação bilíngue. De tal forma, com vistas a provocar mudanças neste panorama, faz-se necessária a realização de pesquisas sobre a estrutura da língua de sinais como suporte para a reflexão sobre encaminhamentos de ensino voltados para uma proposta que precisa considerar o uso de duas línguas. Nesse sentido, um dos pontos que suscitaram questionamentos possíveis de estudo refere-se à organização aspectual na Libras e a interferência desta na aquisição do português escrito por surdos. Considerando tais fatos, este trabalho tem como foco temático a aquisição do português escrito por surdos, destacando a análise da organização aspectual em textos de base narrativa como exemplificação do processo de estruturação linguística em textos produzidos por estudantes surdos do ensino fundamental.

Desse modo, aprofundaremos as reflexóes sobre a estrutura da Libras, com o objetivo, ao mesmo tempo, de contribuir para a valorização dessa língua e reforçar a importância da educação bilíngue para as pessoas surdas, compreendendo o processo de ensino/aprendizagem da escrita do português como oportunidade de ampliação de saberes, ou seja, de desenvolvimento de possibilidades distintas de letramento. Para tanto, este artigo está organizado em três partes. A primeira apresenta a metodologia de pesquisa empregada para a realização da análise; a segunda traz uma discussão teórica sobre a questão da aquisição da escrita por alunos surdos e a formação de interlíngua; já a última parte mostra a análise sob o enfoque de estudos linguísticos voltados para a descrição da categoria tempo/aspecto. 


\section{Metodologia de Pesquisa}

Este estudo retoma a concepção teórica e a descrição da organização das categorias tempo e aspecto de Castilho (1966) e Comrie (1976), além de uma revisão bibliográfica referente à aquisição de linguagem e formação de interlíngua, focalizando a aquisição do português escrito por surdos, haja vista o caráter exploratório/qualitativo desta pesquisa, a qual busca analisar os dados coletados e observar o emprego da categoria aspecto à luz das teorias linguísticas. Para tanto, também as obras de Jake (1998) e de White (2003), entre outros, são consideradas.

Os dados aqui apresentados são de dois tipos: ${ }^{1}$ (a) textos de base narrativa produzidos por alunos surdos do $7^{\circ}, 8^{\circ}$ e $9^{\circ}$ ano do ensino fundamental; e (b) questionário respondido por esses mesmos estudantes com o intuito de conhecer os perfis de aquisição de linguagem deles. Esses alunos são de uma escola pública da cidade de Curitiba-PR e estão em turmas formadas apenas por surdos, mas com professora ouvinte auxiliada por intérprete. A pesquisa foi realizada com 5 alunos com idades entre 14 e 17 anos ( $8^{\circ}$ ano), 3 alunos com idades entre 13 e 19 anos ( $7^{\circ}$ ano) e 5 alunos ( $9^{\circ}$ ano) também com idades entre 13 e 19 anos. Os alunos foram convidados a participar de uma atividade de escrita, acompanhados pela professora e pela intérprete. Essa atividade teve início com a apresentação de um vídeo ("Os reis do circo do desenho animado Tom e Jerry") ${ }^{2}$ para a ativação do conhecimento prévio dos alunos sobre a temática que seria usada para a produção. Em seguida, realizou-se uma modelização de narrativa ficcional. A escolha de se trabalhar a partir da noção de gênero surgiu pela necessidade de se verificar usos da estruturação gramatical da escrita do português. Para isso, considerou-se que os gêneros textuais, conforme Schneuwly e Dolz (2004), são bases que orientam as ações discursivas, as quais, por sua vez, são resultados de práticas sociais que têm sua estrutura definida por um objetivo específico. Nesse sentido, a estrutura de gêneros de base/tipo narrativa pode apresentar uma maior ocorrência de organização aspectual, visto que a temporalidade é uma característica da organização mais estável desse tipo textual. Para a produção, os alunos deveriam recontar a história a que assistiram com o vídeo, sem a interferência leitora das professoras.

\footnotetext{
${ }^{1}$ Os dados foram coletados com a ajuda da aluna de PIBIC, Fernanda Alves.

${ }^{2}$ Esse vídeo foi escolhido por não apresentar legenda em Língua Portuguesa e por ser um desenho que conquista a atenção de leitores jovens e adultos.
} 
O questionário preenchido pelos alunos tinha como objetivo coletar, principalmente, informaçôes sobre a idade com que eles adquiriram a Libras, se eram filhos de ouvintes ou surdos, se passaram por processo de oralização ou não, se estudaram em escolas com propostas bilíngues ou não. Antes de apresentar a análise dos dados, com a finalidade de averiguar a organização de textos escritos por alunos surdos - tendo como hipótese a formação de interlíngua nesse processo e exemplificando tal formação pelo sistema aspectual -, o próximo item expõe a discussão teórica que norteia a investigação realizada na sequência.

\section{A questão da escrita na proposta de educação bilíngue para o aluno surdo}

Uma das questões que se abordará aqui é por que não valorizar também a modalidade escrita das línguas de sinais para o ensino/aprendizagem em uma perspectiva bilíngue para o trabalho com alunos surdos, no sentido de que esse pode ser um encaminhamento que ajudaria a diminuir a cristalização de organizaçõos de estruturas de interlíngua nos textos desses alunos. $\mathrm{Ou}$ seja, a sugestão que se faz neste artigo é de que se avalie o papel da escrita de língua de sinais em um processo educacional de bilinguismo diglóssico. ${ }^{3}$ Essa sugestão se sustenta com base nos pressupostos teóricos sobre interlíngua, pois é possível pensar que, justamente, algumas respostas sobre o processo de aquisição em uma perspectiva mais voltada para o sistema linguístico possa trazer propostas diferentes para se pensarem estratégias de ensino com o objetivo de aprofundar os diferentes graus de letramentos.

Para tanto, vale lembrar que, no que diz respeito ao ensino/aprendizagem de línguas por pessoas surdas, os estudiosos ${ }^{4}$ de aquisição de linguagem enfatizam, hoje, a ideia de que toda criança surda deveria crescer em um ambiente bilíngue. Tal concepção propõe o uso da língua de sinais como L1 e da oral como L2 (em sua modalidade escrita e quando possível em sua modalidade falada), pois as pesquisas indicam que, dessa maneira, as crianças conseguiriam desenvolver melhor suas capacidades cognitivas, linguísticas

\footnotetext{
${ }^{3}$ Em um bilinguismo diglóssico, reforça-se a necessidade de o sujeito surdo adquirir uma língua de sinais primeiro, portanto, como a materna, e depois, o sistema escrito da língua oral apenas para uso em situações sócio-culturais específicas.

${ }^{4}$ Entre eles, Grosjean (2001), Ramsey \& Noriega (2001), Ferreira-Brito (1989), Felipe (1989), Martin (2001), Bonvillian \& Siedlecki (2000), entre outros.
} 
e sociais, uma vez que, por meio da linguagem, principalmente da Libras, aprimoram habilidades como abstração, memorização, que são críticas para o desenvolvimento pessoal. Dessa maneira, a proposta de bilinguismo tem que ocorrer de modo apropriado para os interlocutores e a situação, lembrando que os surdos se valem da língua de sinais e, em algumas situações sóciodiscursivas, da modalidade escrita da oral, ainda, em outras ocasiōes, serão as duas línguas em alternância.

É claro que a base dessa formação bilíngue deve ser a língua de sinais - língua adquirida de modo natural pelos surdos, no processo de interação -, o que se destaca aqui é o papel também da escrita de sinais no sentido de ser importante na constituição da identidade linguística/social/cultural do surdo e ajudar no reconhecimento de uma estrutura linguística da escrita da segunda língua. Considere-se, por exemplo, que, para Vygotsky (1991), quando a criança brinca e reverte significados dos objetos, ela estaria se valendo de simbolismo de segunda ordem e, por conseguinte, isso a auxiliaria a compreender a escrita. Assim, quando ela desenha e percebe tal atividade como uma representação da fala, inicialmente, para a criança ouvinte, a modalidade oral de linguagem é representada por símbolos escritos; porém, quando compreende as relações entre grafemas e fonemas, a escrita passa a ser um simbolismo direto (primeira ordem), isto é, passa a ser compreendida sem o vínculo intermediário com a oralidade. Segundo Braslavsky (1992), os rabiscos iniciais das crianças são um simbolismo de primeira ordem por representarem diretamente o significado pretendido; depois, ao ser mediada pela fala, a escrita passa a ser simbolismos de segunda ordem; quando a criança prescinde da fala, a escrita volta a ser de primeira ordem.

No caso da criança surda, é possível pensar que os sinais da sua língua contêm "a futura escrita" dessa criança e uma representação desses sinais pelo signo escrito são a fixação dos significados compreendidos na Libras. A escrita seria, como para a criança ouvinte, em um primeiro momento, a fixação dos sinais no papel, para depois se tornarem símbolos de primeira ordem. A questão que se coloca é como a criança surda pode tomar a escrita da língua oral com simbolismo de primeira ordem sem passar pelo vínculo como a oralidade. Qual é a compreensão dela dessa forma linguística? Como e quando, de fato, os traços no papel ganham intençóes e significados tornando-se representações identitárias dessas crianças.

Assim, o que se propõe neste artigo é que aconteçam reflexões sobre como deve realmente ser o encaminhamento de ensino bilíngue para os 
alunos surdos, considerando o papel da escrita de ambas as modalidades linguísticas com as quais ele atuará na sociedade. Os dados aqui analisados mostram, a partir de uma investigação da organização do sistema aspectual, que há cristalizações em alguns usos linguísticos, nos textos de alunos surdos, que podem ser decorrentes da não percepção das relações entre Língua Portuguesa e sua modalidade escrita e Libras e sua modalidade escrita e a própria escrita como simbolismo de primeira ordem, o que leva à produção de sistema de interlíngua.

Quer dizer, os alunos surdos são mergulhados no universo da língua escrita, por meio de sistematização, sem vivência natural com essa modalidade. Desse modo, considerando que a maioria dos surdos não possui contato ou apresenta dificuldades em relação ao português oral, a base para o aprendizado do português escrito é a Língua de Sinais e os dois sistemas ficam "misturados". Grosjean (2001) tem demonstrado que as melhores habilidades das crianças surdas são em língua de sinais. Conforme o autor, as competências linguísticas adquiridas em sinal, tais como regras de discurso, podem ser transferidas para a aprendizagem da linguagem oral, ou seja, melhor as crianças usarão essa modalidade linguística. Então, é possível pensar que as habilidades de escrita geral podem se desenvolver melhor por meio da escrita de sinal.

Defendido esse ponto de vista, é preciso explicar como se dá a formação de interlíngua na perspectiva teórica aqui proposta, a qual considera a língua de sinais como L1 para os surdos, pois é adquirida de forma espontânea por eles, diferentemente da língua oral, aprendida de forma sistematizada, com interação truncada. De acordo com White (2003), o processo de aquisição da primeira língua é desencadeado por meio da interação com o ambiente quando é ativado o estágio inicial da Gramática Universal, ou seja, quando conjunto universal de princípios gramaticais para todas as línguas começa a ser executado mentalmente pelo falante que, gradualmente, seleciona regras disponíveis nesses princípios, em consonância com parâmetros dados pelas diferentes organizaçôes linguísticas possíveis nas línguas humanas.

UG constitutes the child's initial State (So), the knowledge that the child is equipped with in advance of input. The primary linguistic data (PLD) are critical in helping the child to determine the precise form that the grammar must take. As the child takes account of the input, a language- specific is built up, and parameters of UG are set to values appropriate for the language in question. The grammar $(\mathrm{G})$ may be restructured over the course of the time, as the child becomes responsive to different properties of the input. (WHITE, 2003: 2). 
Ao que se refere à fase inicial para a aquisição de L2, a questão que se coloca é se, como no caso da língua materna, a Gramática Universal estaria totalmente disponível para a aquisição de segunda língua ou apenas conjuntos de domínios específicos - aqueles parametrizados para a primeira - poderiam ser acessados? $\mathrm{Ou}$, ainda, se o acesso se torna nulo para aquisição de L2 a partir da hipótese de existência de uma idade limite, de um período crítico/ sensível para essa aquisição? Para esta pesquisa, a hipótese válida, seguindo Jake (1998) e White (2003), entre outros, é a que considera o acesso parcial ou indireto à GU, ou seja, o acesso aos princípios da Gramática Universal se daria via parâmetros estabelecidos para a L1. Em outras palavras, a aquisição de segunda língua ocorre por meio da estrutura da língua materna, e o falante tem a propensão para transferir os valores paramétricos dessa para aquela até a estabilização dos conhecimentos da L2. Nesse processo, conforme as autoras, o aprendiz teria que reformular os parâmetros de L1 para L2 e, então, surge a formação de uma interlíngua: um sistema linguístico autônomo, com suas próprias regras gramaticais compostas pelos princípios de ambas as línguas. Jake (1998) exemplifica esse sistema linguístico com a sentença "In the lake of Maracaibo was discovered the oil", produzida por uma falante de espanhol aprendendo Inglês como L2 (nível intermediário), com a regra paramétrica da L1, que permite a inversão da posição entre sujeito e verbo para ênfase sendo aplicada ao Inglês, língua que não parametriza essa inversão. Assim, com a intenção de atingir seu objetivo comunicacional usando a L2 em processo de aprendizagem, o falante se vale da regra de sua língua materna.

Outro exemplo de formação de interlíngua pode ser visto no trabalho de Santos (2009) com produçôes em Libras por alunos surdos, com idade entre 10 e 18 anos, cursando as séries iniciais do ensino fundamental. A pesquisadora mostra como ocorrem trocas na ordem das palavras nas sentenças escritas em Língua Portuguesa, as quais se aproximam da organização sintática da Libras: "Gosta ele a casa"; "Eu milho é gosta". Nesses exemplos, fica claro o uso das marcas de não flexão para concordância, característica de alguns verbos da Libras, entre eles, GOSTAR. Esse tipo de construção é bem conhecido por professores e pesquisadores da área de linguagem e surdez. Finau (1996) apontou como o processo de aquisição tardia da Libras pelas crianças surdas e a ausência de um trabalho de educação bilíngue podem levar a uma fossilização de estruturas do texto escrito que remetem tanto à organização paramétrica da língua de sinais quanto da Língua Portuguesa, mas sem estarem de fato adequadas nem a uma, nem a 
outra modalidade linguística. Entre as regras "misturadas", a autora observou, além da questão da concordância, o uso de complementizadores e preposição.

É preciso salientar que, embora essa formação de interlíngua esteja presente nos dados analisados, as produções geralmente conseguem cumprir seu papel comunicativo, pois a força semântica estabelece certa coerência textual, apesar de a organização sintática ser diferente do esperado para a L2. Por isso, é interessante investigar em textos de base narrativa o uso da categoria aspectual/temporal, pois, nesses textos, essa estrutura faz parte do estabelecimento da coerência do discurso. Com relação a esse processo de escrita, Andrade (2010) alerta para o fato de que

[...] as características da escrita dos surdos são dinâmicas e dependentes de vários fatores, como, por exemplo, competência no uso da língua e interesse pela escrita, mediação entre professor e aluno via intérprete, metodologia utilizada pelos professores, motivação e habilitação dos educadores para ensinar a sujeitos surdos e outros. [...] concordamos com a afirmação de Everhart e Marschark (1988), que as crianças surdas são, cognitiva e linguisticamente, mais competentes do que concluem os testes a que são submetidas, e com a perspectiva de Sánchez (1999), de que o desenvolvimento normal (funcional) da linguagem e da inteligência parte da sua imersão em situações que lhe facilitem a construção de representaçôes sobre as formas da linguagem constituída e do acesso dos surdos aos vários contextos de produção linguística. (ANDRADE, 2010: 1)

Brochado (2003) apresenta uma síntese sobre o conceito de interlíngua e afirma que há um estágio em que os aprendizes utilizam-se das regras da L1 para melhorar seu desempenho na L2. Assim, de acordo com a autora, um sistema de interlíngua apresenta trocas morfológicas (concordância nominal e verbal) e uso de estratégias de comunicação diferenciadas para solucionar problemas que surgem durante a interaçãa. A conclusão de Brochado (2003) em sua análise é interessante porque defende que as crianças surdas são capazes de se apropriar de uma segunda língua sem o apoio da oralidade, pois, de acordo com a autora, a aquisição da escrita da Língua Portuguesa por alunos surdos é mediada pela língua de sinais. Então, é válido levantar a hipótese de que a aquisição da escrita representativa da modalidade de língua viso-espacial possa ser o melhor caminho para auxiliar também a aprendizagem da escrita da língua oral, como se propõe aqui. 


\section{A análise}

\subsection{Antes, as categorias tempo e aspecto em análise}

Para a análise dos dados, o foco está na organização das categorias tempo/aspecto nos textos produzidos pelos informantes. Mais comumente, quando se pergunta sobre tempo nas línguas, pode-se ouvir, por exemplo, que ele indica o momento em que as ações verbais acontecem, pensando simplesmente nos tempos ditos naturais: presente, passado e futuro. $\mathrm{O}$ aspecto, por sua vez, seria responsável pela interpretação de uma ação como concluída ou não, observada na sua duração ou repetição.

Todavia, a questão não é tão simples assim, pois a noção de aspecto na literatura, quase sempre, relaciona dois fenômenos temporais: uma propriedade temporal inerente às situações em si, expressada por verbos (Aktionsart) e a outra referente a diferentes maneiras de pressentir situaçôes dadas por propriedades da predicação verbal. Tais propriedades podem denotar ocorrências pontuais - o início e o final da ação coincidem - ou ocorrências incompletas, continuadas, isto é, sem desfecho. Para a primeira situação, a interpretação é de aspecto perfectivo e para a segunda de imperfectivo. De uma forma simplificada, pode-se dizer que analisar como se dá a organização de tempo e aspecto nas línguas é tentar descobrir como os falantes produzem e interpretam sentenças isoladas ou em sequências discursivas com significado temporal. É possível que, para isso, seja necessário o falante recorrer a conhecimentos de ordem cognitiva, cultural e linguística (elementos internos e externos).

Ilari (1997) analisa as construções temporais como "relações cronológicas". Para o autor, a localização no tempo dos atos, estados e processos, ou seja, das questões aspectuais expressas pelas sentenças da língua, é basicamente o resultado de uma construção. Segundo o autor, essa construção envolve morfemas verbais, os auxiliares, os adjuntos e, eventualmente, informaçóes que se buscam em lugares bem determinados do contexto. Ilari (1997) ainda afirma que certas relaçōes aspectuais funcionam como um cálculo e todo o predicativo comporta um "esquema temporal subjacente". Ou seja, a expressão aspectual pode não se dar apenas com a forma verbal, mas como resultado da combinação da semântica do verbo com as flexões gramaticais, com as expressões temporais (adjuntos adverbiais, por exemplo) e com os argumentos verbais. Além disso, embora haja uma relação 
forte entre as categorias tempo e aspecto, pois ambas, conforme Castilho (1995), podem ser concebidas como propriedades de predicação, nesta análise é levado em conta o fato de que tempo - diferentemente de aspecto - estabelece relações dêiticas, por estar vinculado com o tempo de fala.

De acordo com Castilho (1995), o aspecto pode se manifestar gramaticalmente ou lexicalmente (Aktionsart). No caso da Língua Portuguesa, por exemplo, há flexões de gerúndio que produzem uma leitura imperfectiva (eventos descritos sem ponto final no tempo: Maria está cantando no jardim.) ou as de pretérito perfeito, que por sua vez podem denotar perfectividade (eventos descritos em um ponto marcado no tempo: Maria cantou no jardim.). Já o aspecto lexical caracteriza-se por propriedades aspectuais inerentes ao verbo e a outros itens lexicais empregados pelo enunciador. Por exemplo, é possível perceber a perfectividade inerente à semântica do verbo "morrer" e a imperfectividade em "passear".

No entanto, esses valores aspectuais, como observado por Ilari (1997), podem ter diferentes leituras quando entram em jogo a lexicalidade, a flexão morfológica, os adjuntos da sentença, a quantificação de forma composicional e todo o predicativo se comporta como esquema temporal subjacente: Maria estava cantando no jardim às 15 horas; Maria sempre cantou; Maria estava morrendo lentamente na UTI; Maria passeou com o filho ontem à tarde. Note-se que nessas sentenças a leitura aspectual é alterada pela relação semântica de expressões que fecham o intervalo de tempo (End Points) ou, ao contrário, por aquelas que expressam um intervalo aberto para a realização dos eventos, juntamente com as mudanças de flexão para tempo nos verbos. Por conseguinte, a aspectualidade é dada pela composição entre os sistemas semântico, sintático e pragmático.

Com relação à descrição das categorias tempo e aspecto nas línguas de sinais, entre outros trabalhos há o de Fischer (1973) com a afirmação de que aspecto é marcado morfologicamente nessas línguas, por repetição de um movimento, por exemplo. Segundo a autora, na maioria das línguas faladas, as palavras morfologicamente complexas são, geralmente, formadas pela adição de prefixos e sufixos à palavra raiz. $\mathrm{Na}$ Língua Americana de Sinais, essas formas são criadas alojando-se um sinal raiz (mantido ou repetido) dentro de planos ou contornos de movimento dinâmico no espaço. Fischer (1973) informa, ainda, que essa língua tem muitas flexôes verbais responsáveis pela leitura da informação temporal sobre a ação, por exemplo, se ela é habitual, repetitiva ou contínua. 
Com relação à Libras, Finau (2004) propõe que a leitura aspectual ocorre, nessa língua, de forma dinâmica, por meio de uma organização flexional do sistema linguístico mais a interpretação da composição sintáticosemântica dos enunciados, em interação com princípios pragmáticos. A organização da aspectualidade se dá pela lexicalidade verbal, pela flexão morfológica dos verbos (alterações dos parâmetros direção DIR e Movimento, por exemplo) e pela interferência da referenciação temporal, a qual é denotada por operadores temporais como os sinais PASSADO, FUTURO e HOJE, além de expressōes como "End Points" que realizam restrição nos intervalos de tempo. Vale destacar que a alteração do parâmetro DIR também é responsável pela marcação de tempo: a direção dos movimentos dos sinais para trás e/ou para baixo e para frente e/ou para cima é determinante para estabelecer as noções, respectivamente, de passado e futuro, mais do que a linha imaginária que estabelece o espaço de sinalização.

Morfologicamente, o aspecto imperfectivo, na Libras, é realizado pela alteração do parâmetro movimento (amplitude, duração, velocidade) e DIR, nos sinais de verbos ou em operadores temporais. As alterações morfológicas são empregadas para tornar o sinal mais lento e contínuo; vale notar que a direção, geralmente, é mudada de direta para semiarco. Já o Perfectivo, dado também pelo emprego de operadores temporais específicos para fechar um evento, tem alteração na realização dos sinais de verbos que tornam os movimentos abruptos e retos. Por último, o aspecto iterativo tem realização mais rápida e ocorre com mais modificações do parâmetro configuração de mãos e articulação de braços. A alteração direção do sinal, de reto para semiarco, também é frequente. Além disso, não há marca para pontuar a finalização da repetição do evento. A repetição do próprio sinal do verbo ou o uso de redobro (sinalização com duas mãos quando a raiz do verbo exige apenas uma) também é empregada para esse caso. $\mathrm{O}$ parâmetro expressão facial também é modificado.

Conforme a pesquisadora, os dados da Libras apontam, portanto, para a existência de um sistema de composição semântica entre o emprego desses operadores temporais/aspectuais, os valores aspectuais dos verbos (Aktionsart) e a relação desses com os argumentos do predicado e, ainda, os fatores pragmáticos envolvidos no sistema linguístico, por exemplo, com o conhecimento compartilhado fazendo parte da restrição temporal na Libras por meio de pressuposições pragmáticas. Ou seja, informações temporais e aspectuais nessa língua são expressadas, indiretamente, na estrutura 
linguística e, assim, presumidas por default. Os elementos avaliados para corroborar essa proposta advêm dos seguintes fatos: (1) o tempo futuro, na LIBRAS, tem uma estrutura estereotipada, precisando sempre do operador temporal dado pelo sinal FUTURO para ser denotado, e isso pode ser previsto pelas heurísticas propostas por Levinson (2000): "o que não é dito, não é" - se não há marca para futuro na sentença, não é futuro; (2) o passado pode ter operadores como PASSADO, ANTES ou ser dado pelo aspecto perfectivo dos verbos, ou seja, a leitura se dá também pela heurística anterior e mais a de que "o que é expressado simplesmente é uma exemplificação estereotipada" $e$ pelo aktionsart, e (3) o presente é marcado justamente pela ausência de marcas de passado ou futuro, isto é, entra em jogo a heurística "o que é dito de uma maneira anormal, não é normal". Assim, o presente é dado por default, ou seja, por contraste significativo verificado por meio dessa heurística ou pelo uso do operador HOJE.

Essas heurísticas propostas por Levinson (2000) estão diretamente relacionadas às máximas de Grice (1967). A primeira (o que não é dito, não é) retoma a máxima de Quantidade, a qual determina que o falante faça com que sua contribuição seja tão informativa quanto requerida. A segunda (o que é expressado simplesmente é uma exemplificação estereotipada) pode ser relacionada diretamente à segunda máxima de Quantidade: o falante não deve fazer sua contribuição mais informativa do que o requerido. A ideia subjacente é evitar dizer o que não pode ser garantido. Já a terceira heurística (o que é dito de uma maneira anormal, não é normal) pode ser vinculada à máxima de Modo, especificamente com as submáximas: evite obscuridade de expressão e prolixidade.

Essa proposta para explicar o funcionamento do sistema linguístico da Libras para denotar tempo/aspecto é aplicada, a seguir, na realização da análise dos textos produzidos pelos alunos que contribuíram para esta pesquisa. Para investigar se há formação de interlíngua no processo de aquisição da escrita por alunos surdos, a organização aspectual, tanto da L1 quanto da L2, será considerada a fim de verificar o sistema intermediário entre as duas línguas, pois, como tal organização, aqui, é tomada como uma composição entre sintaxe, semântica e pragmática, ela permite um olhar mais amplo sobre a estrutura em uso pelos alunos. 


\subsection{Os dados em análise}

Para iniciar a apresentação dos dados são consideradas, a seguir para investigação qualitativa -, algumas informações importantes obtidas a partir das respostas dadas, pelos alunos participantes, ao questionário. $\mathrm{O}$ primeiro ponto diz respeito ao fato de que, dos 13 alunos envolvidos nesta tarefa, apenas 4 (L.2 , S.1, M.1 e Z.1) ${ }^{5}$ sempre estudaram em escolas que tinham a Libras como base para a educação, e desde os 4 anos são usuários da língua de sinais. Os outros passaram por escolas regulares até agora e foram submetidos ao ensino predominantemente oralista, vieram a adquirir a Libras já na pré-adolescência. Apesar disso, a relação do grupo com o ensino de Língua Portuguesa, em sua maioria, não parece ser de desmotivação ou contrariedade, como é possível observar em relatos como o de Z.1 e L.2 ao responderem à questão do questionário sobre a aprendizagem da língua oral: ${ }^{6}$

Eu gosto de escrever em português porque meu jeito tem vontade de escrever e desenhar, preciso aprender frase certa. (Z.1).

Eu fui gostando e querendo aprender mais o português, e o português é muito bom pra quem tem dificuldades e pra quem quer aprender mais. (L.2).

Vale destacar que, exatamente, os participantes que adquiriram Libras na primeira infância, por volta dos 4 anos, declararam, em suas respostas ao questionário, ter facilidade para escrever. Isso mostra que as pesquisas cuja orientação é a de afirmar a necessidade de os surdos terem acesso, o mais rápido possível, à língua de sinais para constituírem-se como sujeitos sociais e, também, para terem ampliado o caminho de aquisição da escrita (e para aqueles que desejarem, da oralidade) são corroboradas pela própria percepção dos alunos adolescentes quando questionados sobre sua aprendizagem linguística. Essa confirmação se sustenta da mesma forma na situação inversa, quer dizer, quando os alunos mais velhos (17 a 19 anos), que adquiriram Libras tardiamente, refletem sobre seu aprendizado da Língua Portuguesa e mostram-se desmotivados com essa atividade:

\footnotetext{
${ }^{5}$ Os nomes dos alunos participantes da atividade para a produção desta investigação foram retirados e aparecem aqui apenas indicadores para a referenciação e retomada de dados pela pesquisadora.

${ }^{6}$ As perguntas eram: 5) Na sua opinião o uso da língua portuguesa é ( ) Fácil ( ) Médio ( ) Difícil. Por quê? 6) Gosta de escrever em português? Por quê?
} 
Porque é aprender pouco médio porque eu muito preguição.(E.1)

Porque é fácil e dificil pra mim de vez em quando tenho dificuldade de entender o português. (G.1)

Embora o questionário não fosse o foco para a análise, mas sim a produção do gênero de narrativa ficcional, ele permitiu algumas análises qualitativas importantes como essa. Além disso, orientou muito o olhar para os dados por trazer a informação sobre quando os alunos iniciaram o contato com a Libras em suas vidas. Por exemplo, G.1 (13, $7^{\circ}$ ano) só começou a usar língua de sinais com 12 anos (e é pouquíssimo oralizado), ou seja, apenas há um ano antes desta pesquisa. Ele relatou que tem muita dificuldade para ler e escrever, apesar de gostar da disciplina de Língua Portuguesa e achá-la importante, mas ele próprio percebeu (informação confirmada oralmente pela professora) que está escrevendo melhor e compreendendo mais depois que passou a usar Libras. O interessante é que, em seu texto, já é possível verificar que o processo de formação de interlíngua está em jogo para as categorias aqui investigadas, pois as marcas de tempo pelo uso de operadores como DEPOIS para interromper a situação imperfectiva dada pelo presente por defaulté realizada como na composicionalidade do sistema da Libras na escrita do português.

Gato mata rato pegar correr depois rato macaco. Gato leão pular rato ah ah ah ah lindo. (G.1)

Conforme Finau (2004), os operadores DEPOIS, FUTURO, ANTES, geralmente, são usados para denotar o tempo de um turno completo, por isso, na maioria das suas ocorrências, já aparecem no início dos enunciados. O valor temporal dado pelo operador é mantido até que se coloque outro ou se passe o turno de fala, como acontece com o verbo "pular" na sentença em (e) que recebe o valor de passado dado pela continuidade da sentença anterior. Retomando Jake (1998), é possível pensar que a L1 está servindo de apoio para estruturar a L2 e a análise tempo/aspecto fornece pistas para sustentar essa hipótese. Outros exemplos para comprovar essa hipótese são os dados de F.1 (12, $7^{\circ}$ ano), que adquiriu Libras com 4 anos, e de D. 1 (14, $7^{\circ}$ ano), com aquisição de Libras aos 6 anos. Esses dois alunos têm opinióes parecidas sobre o aprendizado da escrita, isto é, que é uma atividade razoavelmente difícil, porém gostam muito de escrever e ler - destaca-se o bom relacionamento com a professora de Língua Portuguesa. Os textos 
desses dois participantes da pesquisa já demonstram um afastamento maior da estrutura da Libras e da escrita do português, pois apresentam flexões de concordância em verbos que, na língua de sinais, não são empregados com alteração de movimento direcional (DIR) para marcar a relação entre o verbo e seus argumentos e não recebem flexão para marcar passado. No entanto, o uso do operador temporal, novamente o DEPOIS, permanece para denotar a aspectualidade da narrativa.

Gato pegou rato no circo depois ele rato deixou elefante. (D.1)

Parabéns gato depois gato usa bolinha um gato 4 leão usa bola depois pular alto canhão. (F.1)

A mesma situação pode ser observada para três alunos do oitavo ano, com aquisição de Libras na primeira infância, 4, S.1 e Z.1, ambos com 14, e M.1 com 13 anos. Todos afirmaram no questionário ter facilidade para escrever e ressaltaram a importância de usarem a escrita. Nos textos produzidos por eles, também se observa um distanciamento entre o sistema linguístico da L1 e da L2, com flexôes de concordância e tempo sendo realizadas nos verbos na escrita do português. O emprego da palavra "após" em vez de "depois" por M1 pode denotar a superação da utilização da marca narrativa em Libras para o uso da estrutura linguística do português. Observem-se os dados:

Jerry fugiu e entrou no buraco de madeira, mas o tom não conseguiu entrar. Após o Jerry chamou o tom, o tom viu e quer pegar. (M.1)

O Tom está correndo pega o Jerry mas o Jerry entra .... o burraco dentro lugar macaco que tom esta assustado. (S.1)

Depois o Jerry esta engraçado que o elefante também engraçado. (S.1)

Quer dizer, quando a criança surda tem mais tempo de uso da Libras e, ao mesmo tempo, está em contato com a escrita da Língua Portuguesa, como defende a proposta de educação bilíngue, maior é o afastamento da estrutura de interlíngua entre L1 e L2. Esse fato corrobora a pesquisa de Brochado (2003) que atribui os bons resultados à produção escrita por alunos surdos vinculados ao bom desempenho deles em Libras, pois a língua materna atua como mediadora no processo de aquisição da L2, proporcionando ferramentas de apoio até a estabilização da língua alvo. Provavelmente, a 
escrita da língua de sinais poderia trazer uma contribuição ainda maior para que as duas línguas fossem usadas com estruturas gramaticais próprias, pois mais cedo o aluno compreenderia que os símbolos da escrita representam os objetos do mundo discursivo assim como a fala ou os sinais.

Outro dado interessante que mostra a interferência da língua materna na produção da segunda língua vem de L.2 (15, $8^{\circ}$ ano), usuária de Libras desde os 4 anos e que, segundo relatado no questionário, gosta de escrever todos os dias para melhorar o uso da Língua Portuguesa. Em seu texto ainda ocorre muito uso de verbo no infinitivo, o que pode denotar a interferência da produção em Libras, na qual o presente é marcado pela ausência de marcas de passado ou futuro, retomando a heurística discutida anteriormente "o que é dito de uma maneira anormal, não é normal", isto é, o presente é dado por default. Mas o que há de interessante nesse dado é a manifestação do aspecto iterativo quase como se a sinalização da Libras estivesse sendo realizada pela repetição do mesmo sinal verbal:

\section{Jerry fica longe caio pula pula pula leão e Jerry. (L.2 $)^{7}$}

Outras ocorrências importantes se dão para os verbos com marcaçōes lexicais para perfectividade e imperfectividade (Aktionsart) em textos de alunos com aquisição de Libras por volta dos 5 anos, mas que já estão frequentando o nono ano escolar. Parece que o trabalho com a escrita do português na escola, ao longo do tempo, exerce certa força para que o aprendiz comece a perceber as diferenças entre os sistemas da L1 e da L2. Observem-se as sentenças de T.1, 17 anos, que gosta de ler histórias infantis, conforme seu relato:

Elefante e girrafa olhar gato correndo que procurar rato fugir. Rato fugir gato viu ele entre casa dentro gato. (T.1)

A flexão de "correr" para denotar imperfectividade pode ser decorrente da percepção do aluno de que esse valor aspectual precisa de uma marca no português, uma vez que na Libras também há flexão para imperfectividade para alterar verbos cujo valor lexical é para leitura perfectiva. Outros exemplos desse ponto aparecem nos textos de G.2 (17, 9 ano) e S.1:

\footnotetext{
${ }^{7}$ É possível pensar que seria uma repetição natural também para a estrutura da Língua Portuguesa, mas provavelmente, para uma criança em início do processo de aquisição de escrita, o que não é o caso aqui.
} 
No circo tom começa correndo atrás do Jerry e tom não consegue dentro do circo. [...] Tom é atingido várias vezes com os personagens do circo que são vários tipos como a foca, o homem e os leôes. (G.2)

O tom está correndo pega o Jerry. (S.1)

Embora a maioria dos dados de alunos que tiveram contato cedo com a Libras mostrem que, realmente, o uso de um sistema linguístico estruturado para a L1 pareça fornecer conhecimento para organizar a gramática da escrita do português como L2, é preciso dizer que alguns casos mostram mais dificuldades, como a produção de R.1 (17, $9^{\circ}$ ano) e J.1 (19, $9^{\circ}$ ano), que adquiriram Libras por volta dos 5 anos. Observem-se os exemplos de sentenças produzidas por eles:

No começo a comer atias de Jerry. [...] Tom Faze e entra numa barroco de elefante vou Feny resolve assusta eles e tom ferna. Tom vou pular foca e Tom Jerry vi muito Jerry e muito bol. (R.1)

Tom vou pular foca e Tom Jerry vi muito Jerry e muito bola. (J.1)

Apesar de os textos desses alunos apresentarem tentativas de flexões verbais do português, a ordem sintática é muito confusa, há troca de vocabulário, como acima, "correr" por "comer". Existem ensaios de marcas temporais também pelo uso de operadores, mas muito mais pelo conhecimento da Libras do que pelo funcionamento sistêmico da escrita da Língua Portuguesa: "começo" - em Libras é muito empregado o sinal COMEÇAR para dar continuidade às narrativas, "vou" pode ser a versão para o operador FUTURO da língua de sinais. De acordo com Jake (1998), no processo de aquisição de linguagem, os morfemas lexicais são adquiridos antes dos flexionais; provavelmente, nesses casos, seja isso que está acontecendo. Os alunos compreendem o valor lexical dos verbos, mas, ao tentar realizar as flexôes para marcar tempo para a continuidade das narrativas, apresentam dificuldades com as categorias funcionais que são parametrizadas de modo diferente pela Libras e pela Língua Portuguesa, principalmente para a marcação de tempo.

Vale considerar, portanto, a partir desses dados que, no processo de aquisição de segunda língua, entram em jogo outros fatores para além do uso ou conhecimento do sistema linguístico. Como aponta Ellis (1997), questões como motivação, interação com professor, objetivos para aprendizagem da L2 interferem no desenvolvimento linguístico dos alunos. Como já 
mencionado no item 4.1, retomando Andrade (2010), a escrita dos surdos é dinâmica e depende de vários fatores, desde a competência para o uso da língua até o estilo de mediação e metodologia do professor. Com relação a isso, é preciso perguntar se entre esses pontos não estaria o conhecimento da língua de sinais, antes de tudo, formando a identidade da criança surda e fornecendo subsídios para a aquisição da escrita da modalidade oral. Os dados analisados mostram que sim, justamente pela formação da interlíngua. O conhecimento da escrita da língua de sinais pode ampliar esse aprendizado e formação do sujeito autor? As indicações da análise também sugerem que sim. Mas isso é suficiente para o aprendizado dessas crianças? Claro que não.

Aqui, é necessária a retomada de alguns relatos dados como resposta ao questionário aplicado para a pesquisa, principalmente, dos alunos do nono ano, que já são jovens adultos (17-19 anos), repetiram séries e estão junto com alunos surdos mais novos que estudaram, quando menores, em escola que utilizava língua de sinais. Esses alunos se sentem inferiorizados, desmotivados para estudar e gostariam de já estar trabalhando e convivendo com amigos da mesma idade. A atitude afetiva negativa em relação à Língua Portuguesa aparece em sentenças como:

Eu tem muito que mais menos portuguesa porque palavras difícil pouco português. (R.1)

Eu não gosto português. Eu gosto muito inglês. (E.1)

Apesar dessas questões, é possível afirmar que há, nos textos produzidos pelos alunos, uma interferência positiva da Libras no aprendizado da escrita da Língua Portuguesa, porque, pela análise das categorias tempo e aspecto, o que se nota, nessas narrativas, são marcaçôes dadas pelo conhecimento da língua de sinais. Quer dizer que se há nesses textos uma estrutura temporal para a narrativa, isso se deve ao conhecimento que o aluno tem de como se faz isso em Libras. Essa afirmação é possível porque, precisamente, a marca aspectual que mais aparece nos textos é para imperfectividade, a qual, na Libras, é diferenciada por realização de alteração morfológica em DIR, movimento e expressão facial. Com relação à denotação temporal, também são os operadores semânticos como o DEPOIS, por exemplo, o que mais é empregado pelos alunos, do mesmo modo como se faz na L1 deles. Assim, a análise das narrativas mostra um movimento de formação de interlíngua para a aquisição de L2 pelos alunos surdos. A questão que merece preocupação é se 
esse sistema misto entre as línguas se torna fossilizado com o passar dos anos, por falta de uma mediação adequada para a educação bilíngue desses sujeitos.

\section{Considerações finais}

A investigação aqui apresentada traz fortes indícios de que, no processo de aquisição de escrita da Língua Portuguesa por alunos surdos, há uma interferência positiva da estrutura da Libras na organização do sistema da L2, uma vez que alunos com aprendizagem da língua de sinais, ainda na primeira infância, parecem conseguir mais rapidamente estruturar o sistema temporal para a produção de narrativas. Não se descarta, no entanto, outras questões que podem estar envolvidas nesse processo, como a relação dessas crianças com a própria aprendizagem da L2 e o encaminhamento de ensino que ainda não privilegia realmente uma metodologia que se valha, por exemplo, da comparação entre as estruturas gramaticais (sintaxe, semântica e pragmática) das duas línguas e o trabalho com a escrita de sinais.

Este trabalho também apresenta dados importantes sobre a formação de interlíngua na aquisição de L2, pois, como defendem, entre outros, Jake (1998) e White (2003), com a análise da organização das categorias tempo e aspecto da Libras e da Língua Portuguesa, é visível a estrutura daquela combinada à gramática da segunda nas narrativas produzidas pelos alunos. Isso também sugere que o acesso a $\mathrm{GU}$, na aquisição de $\mathrm{L} 2$, dá-se por meio da L1, ou seja, indiretamente ou parcialmente.

Isso posto, vale dizer que, embora com dificuldades, e por muita boa vontade da professora que atuava com os alunos que contribuíram para esta pesquisa, há por parte desses alunos - com exceção dos mais velhos - um desejo forte de aprender a escrever em Língua Portuguesa e uma boa relação afetiva com a leitura. Essas indicaçóes apareceram no questionário aplicado para complementar esta investigação. Assim, se a Libras é importante para a constituição do aluno surdo como sujeito social, se ela fornece informações importantes para o aprendizado da estrutura da língua escrita do português, língua esta que é considerada necessária e interessante pelos próprios alunos surdos, confirmando que a Educação Bilíngue é o melhor caminho para essas crianças, por que não ampliar essas possiblidade de aprendizagem com o uso da escrita da língua de sinais? Essa é a principal reflexão que este trabalho propõe para os estudos futuros na área de linguagem e surdez. 


\section{Referências}

ANDRADE, W. T. L. de. Cognição e surdez na educação: a língua em questão. Revista Virtual de Cultura Surda e Diversidade, Editora ARARA AZUL, Edição n.6 / set. 2010, ISSN 1982-6842.

BONVILLIAN, J. D. \& SIEDLECKI JR., T. Young Children's Acquisition of the Formational Aspects of American Sign Language: parental report findings. In: Sign Language Studies, Washinton: Gallaudet University Press, V. I, N. I, Fall, 2000.

BRASLAVSKY, Berta. La escuela puede. Una perspectiva didáctica. Buenos Aires: AIQUE Grupo Editor, 1992.

BROCHADO, Sônia M. D. A apropriação da escrita por crianças surdas usuárias da lingua de sinais brasileira. 2003. 431f. Tese (Doutorado em Letras) - UNESP, Assis. 2003.

CASTILHO, Ataliba T. de. Introdução ao estudo do aspecto verbal na língua portuguesa. 1966. 133f. Tese (Doutorado em Letras) - Faculdade de Filosofia, Ciências e Letras de Marília, São Paulo. 1968. Disponível em: <http://seer.fclar. unesp.br/alfa/article/view/3311/3038>. Acesso em: 29 ago. 2013. 22:37.

CASTILHO, Ataliba T. de; MORAES de CASTILHO, Célia Maria. $O$ aspecto verbal no português falado. In: VIII Seminário do Projeto de Gramática do Português Falado. Campos do Jordão, 1994. (mimeo)

COMRIE, B. Aspect: An Introduction to The Study of Verbal Aspect and Related Problems. Londres: Cambridge University Press, 1976.

ELLIS, R. Second Language Acquisition. Oxford: Oxford University Press, 1997.

FELIPE, T. Bilinguismo e surdez. Trabalhos de Linguistica Aplicada. Campinas/IEL, n.14, p.101-114, jul./dez., 1989.

FERREIRA-BRITO, L. Necessidade psico-social de um bilinguismo para o surdo. Trabalhos em Linguistica Aplicada, Campinas/IEL, n.14, p.89-100, jul./ dez., 1989.

FINAU, R. A. Um estudo das categorias funcionais em textos escritos de deficientes auditivos. Dissertação (Mestrado em Letras), Curitiba: UFPR, 1996.

FINAU, R. A. Os sinais de tempo e aspecto na Libras. Tese (Doutorado em Estudos Linguísticos), Curitiba: UFPR, 2004.

FISCHER, S. Verb Inflections in American Sign Language and Their Acquisition by Deaf Child. Paper presented at the Winter Meeting of Linguistic Society of America, 1973. 
GRICE, H. P. Logic and Conversation. William James Lectures. Harvard University, 1967.

GROSJEAN, F. The Right of the Deaf Child to Grow up Bilingual. Sign Language Studies. Washington: Gallaudet University Press, v.1, n.2, Winter, 2001.

ILARI, R. A expressão do tempo em português. São Paulo: Contexto, 1997.

JAKE, J. L. Constructing Interlanguage: Building a Composite Matrix Language. Linguistics: An Interdisciplinary Journal of the Language Sciences. Belgium: University of Antwerp, v.36, n.2, p.333-382, 1998.

LEVINSON, S. C. Presumptive Meanings: The Theory of Generalized Conversational Implicature. Massachusetts Institute of Technology: A Bradford Book, 2000.

MARTIN, S. D. The English-only Movement and Sign Language For Deaf Learners: An Instructive Parallel. In: Sign Language Studies, Washinton: Gallaudet University Press, V I, N. II, Winter, 2001.

RAMSEY, C.; NORIEGA, A. N. Niños Milagrizados: Language Attitudes, Deaf Education, and Miracle Cures in Mexico. Sign Language Studies. Washington: Gallaudet University Press, v.I, n.3, Primavera, 2001.

SANTOS, Fernanda M. A. dos. Marcas de Libras e indícios de uma interlingua na escrita de surdos em Lingua Portuguesa. Dissertação (Mestrado em Letras) - UFBA, Salvador, 2009.

SCHNEUWLY, B.; DOLZ, J. Gêneros orais e escritos na escola. Tradução de Roxane Rojo e Glaís Sales Cordeiro. Campinas, SP: Mercado das Letras, 2004.

VIGOTSKI, Lev Semenovich. A formação social da mente: o desenvolvimento dos processos mentais superiores. Tradução de José Cipolla Neto et al., 4.ed., São Paulo: Martins Fontes, 1991.

WHITE, Lydia. Second Language Acquisition and Universal Grammar. United Kingdom: Cambridge, 2003.

Data de submissão: 28/02/2014. Data de aprovação: 16/06/2014. 
